УДК 621.003:658.5

$10.17213 / 2075-2067-2019-4-18-24$

\title{
ИНЖЕНЕРНОЕ ОБРАЗОВАНИЕ КАК РЕСУРС ИННОВАЦИОННОЙ ДЕЯТЕЛЬНОСТИ УНИВЕРСИТЕТА: ПРОБЛЕМЫ, ВЫЗОВЫ, ПЕРСПЕКТИВЫ
}

\section{(C) 2019 г. С. Г. Фалько, О. А. Корниенко, Т. Н. Рыюикова}

\section{Московский государственный технический университет им. Н. Э. Баумана}

В статье рассмотрено современное состояние ресурсов инновационной экосистемь университета. Проанализировань пути развития и взаимосвязь науки и практики, а также инновационные процессы в университетах как в системах производства знаний и национальной конкурентоспособности в долгосрочной перспективе.

Ключевые слова: инженерное образование; инновационная экосистема; коммерциализаџия инноващий; ресурсы университета.

The article explores the current state of the university's innovation ecosystem resources. The ways of development and the relationship of science and practice, as well as innovative processes at the university are analyzed.

Key words: engineering education; innovation ecosystem; commercialization of innovation; university resources.

\section{Введение}

Функционирование и развитие инновационной деятельности в техническом Университете опирается на человеческие ресурсы (внутриуниверситетские и внешние), обладающие новыми знаниями по соответствующему направлению, а также и на материальные и нематериальные ресурсы, финансовые источники и инструменты. Многие инженерные решения требуют сегодня смежных знаний, поэтому и инженерное образование должно быть более гибким к требованиям рынка труда.

Человеческие ресурсы, особенно внутренние - это наиболее важная составляющая инновационного процесса любого Университета $[1,2,3]$. Привлечение сторонних кадров - это и дороже, и ненадежнее, хотя в отдельных случаях, когда требуются новые знания, может быть и оправдано.

Рассмотрим, где находятся человеческие внутриуниверситетские ресурсы:

- кафедры (профессорско-преподавательский состав: ППС, аспиранты, студенты);
- университетские научно-исследовательские институты - НИИ (научные сотрудники, инженеры);

- научно-образовательные центры НОЦ (научные сотрудники, инженеры);

- инжиниринговые центры (научные сотрудники, инженеры);

- опытный завод (инженеры);

- малые инновационные предприятия МИП (научные сотрудники, инженеры).

Человеческие ресурсы организаций внешней среды:

- научно-исследовательские институты НИИ и Научно-исследовательские испытательные центры других федеральных органов исполнительной власти (ФОИВ) (Минобороны, Минпромторг, МЧС, Минприроды, ФСБ, РАН и др.);

- конструкторские Бюро - КБ на предприятиях оборонно-промышленного комплекса - ОПК (например, Концерн «Уралвагонзавод» или Концерн «Калашников»);

- R\&D Центры частных корпораций (например, «Лукойл»). 
Привлечение и развитие кадрового состава, во-первых, требует финансовых затрат, а, во-вторых, значительных временных затрат.

\section{1. Интеллектуальные и человеческие ресурсы университета}

В последнее время произошли значительные изменения в характеристиках и состоянии ППС в вузах. В связи с изменениями нормативов часовой нагрузки на преподавателя в 2018 году снизилась вовлеченность преподавателей в совместные прикладные НИР или ОКР. Кроме того, следует отметить, что подготовленные и преподаваемые образовательные программы часто являются «устаревшими» или, точнее сказать, «однобокими». Эта однобокость связана с устаревшей системой образования, когда факультет объединяет только кафедры одного научного направления. Например, робототехника тесно связана с IT, спутниковой связью, новыми материалами и в целом с высокими технологиями (нейронные сети, техническое зрение и т.д.), а также необходимыми знаниями, связанными с постоянными изменениями нормативно-правовой базы (запреты на беспилотные летательные аппараты БЛА, актуализация воздушного кодекса, разрешение на частичное использование автопилота в транспорте и различных помощников), а это дисциплины разных направлений. Кроме того, в мире появляются новые задачи (подводная добыча полезных ископаемых, расконсервация Северного морского пути, создание Арктической инфраструктуры и т.д.), требующие отражения в учебных программах дисциплин. Данные вопросы выходят не только за тематические рамки факультетов и кафедр, но иногда и университетов. Например, в МГУ есть межфакультетский фонд дисциплин, из которого студент может выбрать 1-2 дисциплины по выбору. Данные часы входят в фонд межфакультетской нагрузки. Возможно, необходимо создавать фонды межвузовской нагрузки. Есть направления деятельности, где география и инженерия сходятся вместе.

Интернет-ресурсы могут оказать большую помощь в учебном процессе, например, «Открытый МГТУ» (http://www.open. bmstu.ru/), созданный в МГТУ им. Н.Э. Баумана, «Электронная образовательная система МГТУ им. Н.Э. Баумана» (http://www.e- learning.bmstu.ru). Есть подобные программы и в других вузах. Существуют международные ресурсы, например, «Coursera. Лучшее обучение, доступное во всех уголках земного шара» (https://www.coursera.org/), позволяющие прослушать гибкие и доступные курсы, получить сертификаты и степени онлайн от лучших университетов и компаний мира. Однако, еще далеки от совершенства создаваемые интернет-курсы. Требуется время, заинтересованность преподавателей, возможности для совершенства, кроме того, их необходимо встроить в учебный процесс $[4,5,6]$.

Инженерное образование, в отличие от гуманитарного, требует соответствующей оснащенности, т.е. инженерным университетам требуется новая техника, т.к. сегодняшний уровень оснащенности соответствует международному уровню только в отдельных отраслях, скорее, в передовых. Но есть и базовые направления, например, машиностроительные технологии, которые до сих пор используют оборудование 30-летней давности, а то и старше.

\section{2. Материальные и нематериальные ресурсы инновационной деятельности университета \\ Следующий ресурс - НИИ при уни- верситете.}

Эти структуры функционируют в соответствии с профильными кафедрами. На данный момент существующие подходы получения финансирования разработок и исследований слабо обеспечивают (или вообще не обеспечивают) стабильное денежное содержание научных и инженерных сотрудников. В результате этого научные сотрудники, работающие в НИИ, часто являются совместителями на кафедрах. Положительная же сторона этого момента заключается в том, что научные сотрудники являются практиками, а это хорошо для обучения студентов. Отрицательная сторона связана с тем, что из-за высокой загруженности преподаватели реже хотят сотрудничества $[7,8,9]$.

Для научных подразделений университета характерна совместная работа с организациями внешней среды, подразумевающая, что данные специалисты являются источником исходных данных, постановки задачи в научных исследованиях. Любое сотрудничество 
кафедр и факультетов с внешними организациями всегда положительно для образования. Однако на сегодня в данном сегменте присутствует конкуренция, и она не в пользу университетов.

Предприятия ОПК в последнее десятилетие стараются увеличить свою доходность, используя не только свои производственные мощности для выпуска продукции, но и свои конструкторские бюро (КБ) для участия в конкурсах на НИР и ОКР в Госпрограммах (как ГПВ, так и ГП ОПК). В итоге НИИ и НОЦ университета, ранее выполнявшие совместные работы с КБ, сталкиваются с тем, что, имея большой научный задел, они не в состоянии конкурировать с КБ предприятий ОПК, усиленных собственными производственными мощностями серийного производства.

R\&D Центры частных корпораций (Research \& Development - фактически НИОКР) выполняют широкий спектр задач в своей отрасли. Это центры разработок предприятий реального сектора экономики. Данные центры отличаются тем, что они не занимаются поиском заказов. Задачи и проблемы сугубо в своей отрасли им ставит «материнская» компания. Университету установить и удержать связь с такими центрами, на наш взгляд, крайне тяжело. «Материнскую» компанию в первую очередь будет интересовать кадровый вопрос: поставка специалистов после обучения в университете. В этих центрах существуют свои ускоренные программы обучения, а также наличествует доступ ко всем объектам корпорации для проведения практических работ. Закупки оборудования, материалов и комплектующих происходят в несколько раз быстрее, чем в университете, который имеет статус государственного бюджетного учреждения.

Еще один университетский ресурс -

\section{опытный завод университета.}

Опытный завод университета, как правило, имеет проблемы по загрузке, так как научные коллективы выполняют НИР и ОКР по Гособоронзаказу. Соответственно, финансирование (аванс, закрытие этапов, госприемка) осуществляется в одни и те же периоды по всем заказам. Создается эффект «узкого горлышка», и есть риск не выполнить несколько работ в срок, вследствие чего научные коллективы сформировали свои внешние производственные кооперации, снижая риски производства. Таким образом получается, что помимо проблемы недозагруженности опытного завода университета заказы единичных или мелкосерийных сложных изделий и деталей во внешних производственных кооперациях могут быть также не выполнены в срок в случае появления там большой (а значит и приоритетной) серии. Экономически бывает выгодно заплатить штрафные санкции по контракту с университетом, но взять крупный поступивший заказ и исполнять его в первую очередь.

Тем не менее, опытный завод является серьезной практической базой, также способствующей обучению.

Еще один ресурс - МИП - это ООО с долей университета в учредителях. Данные предприятия призваны помочь университету в качестве инструмента (например, ускоренные закупки). Малые объемы выполненных контрактов на старте, отсутствие различных лицензий приводит к долгой «раскрутке» МИП, и часто они, переходя в операционную стадию, вскоре прекращают свою деятельность.

Итак, это перечислены те организационные структуры внутри университета, с которыми могут сотрудничать преподаватели. Одновременно с научными проектами должны организовываться и финансироваться летние образовательные программы (школы). Образовательные программы должны быть рассчитаны на преподавателей вузов, школьников и школьных преподавателей, которые в летний период могут пройти обучение на программах продолжительностью 2 , 8 и 10 недель. На программы приглашаются школьники, имеющие определенный образовательный уровень. При хороших результатах в течение 3-х лет в летний период они могут пройти полную программу обучения. Преподаватели исследовательских дисциплин должны иметь возможность проводить исследования в научных лабораториях с ведущими учеными. Комбинации исследования должны помогать преподавателям в развивающихся идеях, ресурсах и материалах увлекать и заинтересовывать студентов. После летнего опыта исследования преподаватели 
должны иметь возможность просить финансирование, чтобы купить оборудование для лаборатории и на развитие своего профессионального капитала, то есть на посещение конференций и симпозиумов.

Любой студент, имеющий хорошие рекомендации, может просить 10-недельную летнюю интернатуру в известных лабораториях со стипендией. Сегодня студенты технических факультетов чаще занимаются непрофильными подработками.

Рассмотрим, например, систему обучения в области нанотехнологий. Нанотехнология - мультидисциплинарная область открытия $[10,11]$. Ученые, работающие в физике, химии, биологии, разработке информационной технологии, метрологии и других областях, вносят свой вклад в современные крупные научные достижения.

При подготовке инженеров в области нанотехнологий можно выделить пять видов обучения.

В большинстве стран Европы, а также в США, Канаде и Австралии принята трехступенчатая модель высшего образования. Целью первой ступени обучения, продолжительность которой составляет 3-4 года, является степень бакалавра: Degrees, Graduate, Undergraduate.

Также существуют программы для детей в инженерных школах, которых необходимо подготовить к исследовательской работе: K-12 (программы для детей 12+, летние лагеря).

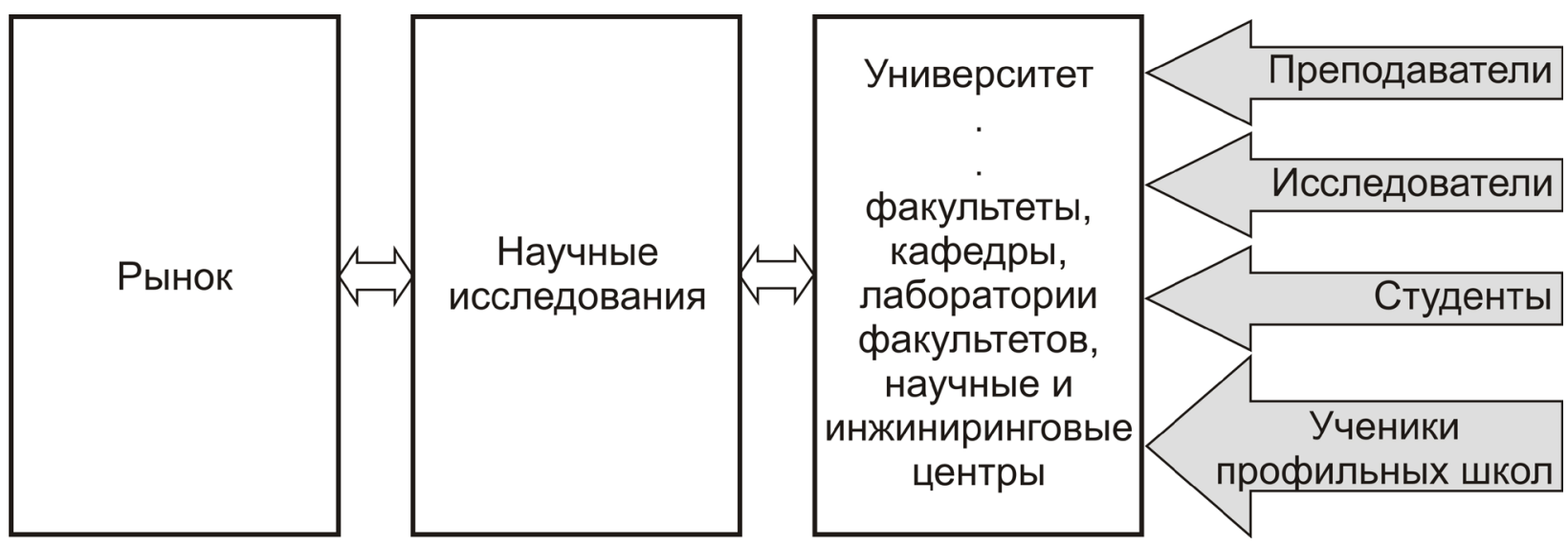

Рис. 1. Система инновационного образования

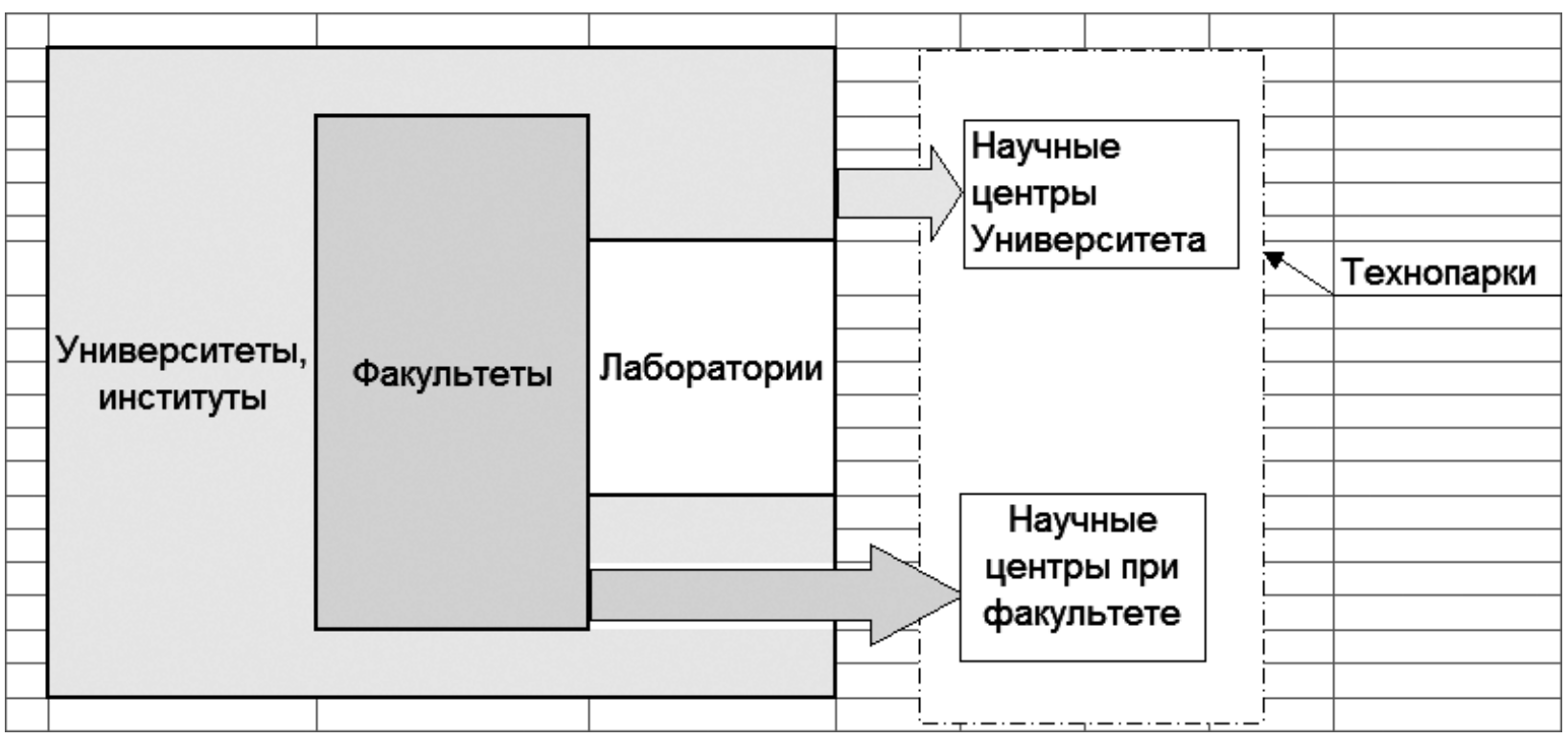

Рис. 2. Образовательные ресурсы инновационной деятельности 
Короткие программы обучения могут иметь как узкоспециализированную направленность (в узкоспециализированных компаниях), так и мультидисциплинарную, в академических научных центрах.

Аналогично строится система обучения в области новых материалов, робототехники и др. $[12,13]$. Комплексного образования требует и экономика и управление системным проектированием.

Таким образом, вся система образования выглядит следующим образом (см. рис. 1). Из представленного рисунка видно, что все участники образовательного процесса должны найти свое место в системе образования.

А для того чтобы факультеты, сотрудники кафедр не теряли связи с практикой, необходимо, каждому факультету иметь непосредственную связь с технопарком и научными центрами (рис. 2).

\section{Выводы}

1. Сегодня многие направления требуют мультидисциплинарного образования. Расчет на то, что электронные курсы решат означенную проблему, на наш взгляд, не оправдается. Подготовка качественного электронного курса длится месяцы, и не факт, что полученный курс позволит решить поставленные проблемы. Скорее, система приглашения практиков для проведения мастерклассов и разбора кейсов может частично решить проблему, но в этой области нет системы. Здесь, скорее, существуют связи и знакомства.

2. При увеличении аудиторной нагрузки даже та часть преподавателей, которая ранее сотрудничала с научными центрами и НИИ, сегодня прекращает свое сотрудничество, что через короткий промежуток времени отрицательно скажется на качестве образования и на научных результатах вуза.

3. Стратегические потери качества образования в результате отрицательно повлияют и на безопасность государства.

\section{Литература}

1. Perkin H. History of Universities. In: James Forest and Philip Altbach, editors. International Handbook of Higher Education. Dordrecht: Springer, 2006. - Pp. 159-205.
2. Etzkowitz H. The Second Academic Revolution and the Rise of the Entrepreneurial Science. IEEE Technology and Society 20 (2): 18-29. - 2001.

3. Берталанфи Л. Общая теория систем: основы, развитие, применение - General System theory: Foundations, Development, Applications. - 1st ed. - N. Y.: George Braziller, lnc., $1968 .-289$ p.

4. Etzkowitz H., Loet Leydesdorff. Universities and the Global Knowledge Economy: A Triple-Helix of University-Industry-Government Relations. - London: Cassell Academic, 1997.

5. Ииковии Г. Модель тройной спирали // Инновации. [Электронный ресурс] 2011. - №4. - Режим доступа: https:// cyberleninka.ru/article/n/model-troynoy-spirali. (Дата обращения: 30.06.2019 г.).

6. Sismondo $S$. An Introduction to Science and Technology Studies. 2nd edition. - Oxford: Willey-Blackwell, 2010.

7. Hegde Deepak. Public and Private Universities: Unequal Sources of Regional Innovation? Economic Development Quarterly 19 (4): 373-386. - 2005.

8. Levy D. Higher Education and the State in Latin America: Private Challenges to Public Dominance. - Chicago: The University of University Press, 1986.

9. Carayannis E., Grigoroudis E. Uadruple Innovation Helix and Smart Specialization: Knowledge Production and National Competitiveness. Foresight and STI Governance. Vol.10. — №1. - 2016. - Pp. 31-42.

10. Boroush M. National Patterns of R\&D Resources: 201415 Data Update. Technical Report NSF 17-311, National Science Foundation, Arlington, VA. - 2017.

11. Модель исследования и инновационной экосистемы для частных университетов - A Research and Innovation Ecosystem Model for Private Universities. The Tecnológico de Monterrey Experience Francisco J. Cantú-Ortiz Tecnológico de Monterrey Introduction.

12. Рыжсикова Т.Н., Боровский В.Г. Проблемы моделирования перспектив модернизации машиностроительных предприятий // Журнал «Проблемы машиностроения и автоматизации». - 2016 г. - №4. - C. 16-25.

13. Фалько С.Г., Рыжикова Т. Н., Баев Г.О. Структурно-логическая модель исследова- 
ния системы управления малыми производственными предприятиями // Вестник ЮжноРоссийского государственного технического университета (Новочеркасского политехнического института). Серия: Социально-экономические науки. - 2016. - №6. - С. 4-15.

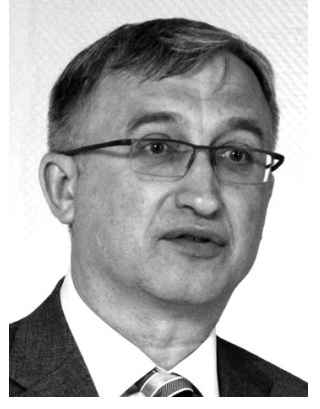

Фалько Сергей Григорьевич - доктор экономических наук, профессор, заведующий кафедрой «Экономика и организация производства» Московского государственного технического университета им. Н. Э. Баумана.

Falko Sergey Grigoryevich - doctor of economic sciences, professor, the head of «Economics and production organization» department of Moscow state technical University named after N.E. Bauman.

105005 , г. Москва, 2-я Бауманская ул., 5, стр. 5, ауд. 520

5 2nd Baumanskaya st., bld. 5, off. 520, 105005, Moscow, Russia

Тел.: +7 (499) 267-00-49; e-mail: serfalk@rambler.ru

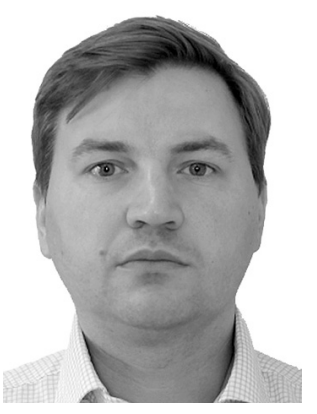

Корниенко Олег Александрович - директор Инжинирингового центра «Автоматика и робототехника» МГТУ им. Н.Э. Баумана.

Kornienko Oleg Alexandrovich - Director of Science Engineering Center Robotics and Automatics BMSTU (SECRA BMSTU).

105005 , г. Москва, ул. 2-я Бауманская, 5, стр. 1

5 2nd Baumanskaya st., bld. 1, 105005, Moscow, Russia

Тел.: +7 (499) 263-61-90; e-mail: bmstu.secra@gmail.com 


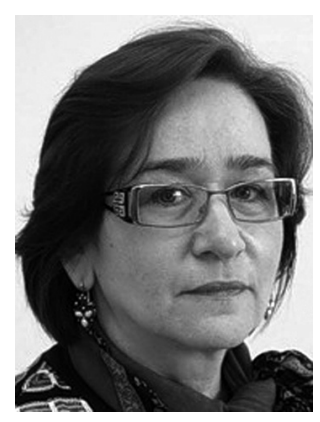

Рыжикова Тамара Николаевна - доктор экономических наук, профессор кафедры экономики и организации производства Московского государственного технического университета им. Н. Э. Баумана.

Ryzhikova Tamara Nikolaevna - Doctor of economic Sciences, Full Professor of chair of economy and organization of production of Moscow state technical University named after N. E. Bauman.

105005, г. Москва, ул. 2-я Бауманская, 5

5 2nd Baumanskaya st., 105005, Moscow, Russia

Тел.: +7 (499) 263-63-91, факс: +7 (499) 267-48-44

E-mail: tnr411@yandex.ru 